\title{
ORTHOSES, PROSTHESES, CONTROLS AND ETHICS
}

\author{
De órteses, próteses, controles e ética \\ Jorge Alberto Langbeck OHANA \\ CBCD North Vice-presidente
}

I

any business relationship - contracts, provision of services or outsourcing -, the contracting party (public or private) has the sacred duty and the full right to audit. The control and evaluation is vital sector for the zeal, care, probity, proper application of funds dispensed to purchase inputs, procedures execution and personnel payment.

To assist in this thorny, but necessary task, there are several instruments as analysis of historical series, protocol obedience and/or guidelines, virtual audits by sampling or, then, permanent in person auditing.

The regulatory team is authorized to question certain procedures, and must have the authority to call the patient to clarify the need of exams that helped in the treatment indication, with the ethical prerogative to contact the applicant professional and discuss unclear aspects. Should call for enlightening conversations doctors who take very different approaches from the usual curve of a control group.

They should be analyzed by the agent that pays for treatment, items on the quality of material to be made used, to avoid arguments that the material of the brand " $\mathrm{X}$ " is much higher than brand " $\mathrm{Y}$ ", forcing, directing the patient to a particular supplier, throwing him against the health plan. It should be established that if certain material is unreliable, ANVISA/MS must be notified to banned it from national use. But, the acting person must be responsible enough to sign the declaration and to have proof about the complaint.

In public affairs, Law 8666 about public biddings and contracts, calls for competitive acquisition prioritizing the best offer, but always respecting the relationship "price + quality"; after all, will be acquired materials or medicines applied in human lives.

The facts reported in the national media bring to the public a fact that is a long time known by medical professionals; medical official representative associations are fighting obstinately against this professional distortion, directing for many years complaints to government agencies. CRM/CFM (Regional Council of Medicine/Federal Council of Medicine) jurisprudence have been applied, punishing numerous professionals for malpractice and unethical conduct, as widely reported nationally in a CFM statement.

The duties of the physician, among others, is prioritize loyalty to the patient, as well as objectivity and professional honesty. The doctor is not in principle responsible for cure, but is to use updated knowledge and the best resources to full patient rehabilitation or palliation, always aiming the quality of life of those who trusted him his health .

Let make clear the condemnation and repudiation of the vast majority of the medical professionals to those working in disagreement, on the margins of what was the commitment adopted at the solemn graduation oath, dishonoring the Hippocratic principles and falling into the temptation of health marketization.

Although this bad specific scenario, it should be highlighted the good performance of the vast majority of the more than four hundred thousand practicing physicians in the country, that follow the rules established for proper practice of the profession. 